\title{
Urinary Symptoms in Multiple Sclerosis: Relation with Urodynamic Findings and Impact on Patient's Quality of Life
}

\author{
Ulas Sungur ${ }^{1}$ (D) Yesim Akkoc $^{1}$ (D) Nur Yuceyar² ${ }^{2}$, Ozgul Ekmekci ${ }^{2}$ \\ ${ }^{1}$ Ege University, School of Medicine, Department of Physical Medicine and Rehabilitation, Izmir, Turkey \\ ${ }^{2}$ Ege University, School of Medicine, Department of Neurology, Izmir, Turkey \\ Correspondence Author: Ulas Sungur \\ E-mail: dr.ulassungur@gmail.com \\ Received: $19.01 .2018 \quad$ Accepted: 07.06 .2018
}

\begin{abstract}
Objective: We aimed to investigate the correlations of urinary symptoms with urodynamic findings in patients with multiple sclerosis (MS) and their effects on quality of life.

Methods: Nineteen MS patients with urinary symptoms were included. The data were obtained from files or with face-to-face interviews. Symptom types of patients were categorized as irritative, obstructive, and mixed. The Incontinence Quality of Life Scale, the King's Quality of Life Questionnaire (KQL) and the International Consultation on Incontinence Modular Questionnaire-Short Form were used to determine the effect of urinary symptoms on quality of life. The Extended Disability Status Scale (EDSS) was used to assess disability. All patients underwent urodynamic examination.

Results: The most frequent finding in urodynamic testing was detrusor overactivity (57.9\%) while $26.3 \%$ had normal urodynamics. EDSS score did not correlate with urinary symptoms or urodynamic findings; it correlated only with the "Role limitation" subscale of the quality of life scales. While there was no relationship between symptom type and quality of life, the rate of detection of pathological findings on urodynamic examination and the bladder capacity in patients with mixed-type symptoms were significantly higher than the patients with irritative symptoms $(p<0.05)$. The "Emotions" and "Sleep/Energy" subscale scores of the KQL were significantly higher in patients with abnormal urodynamic test compared with those without urodynamic pathology.

Conclusion: The urinary symptoms significantly affect the quality of life in MS patients. Since symptoms do not always correlate with the underlying pathology, it is more appropriate to give the treatment based on the bladder type in urodynamic testing.

Keywords: Multiple sclerosis, neurogenic bladder dysfunction, quality of life, urodynamic findings
\end{abstract}

\section{INTRODUCTION}

Multiple sclerosis (MS) is an autoimmune disease of the central nervous system characterized by inflammation, demyelination, axonal loss, and gliosis (1). Urinary symptoms are common in MS patients. They adversely affect the quality of life in MS patients due to their effects on social, occupational, and sexual life (2).

The frequency of urinary symptoms is reported to be 52$97 \%$ in patients with MS (3-4). While urinary symptoms are the initial symptoms in $10-15 \%$ of patients, they are the only symptoms in about $2 \%$ of MS patients (5-7). Irritative urinary symptoms (i.e. frequent urination, urgency, incontinence, nocturia), obstructive symptoms (i.e. difficulty in starting urination, straining to void, incomplete emptying, weak urine flow), or mixed symptoms can be seen in MS patients. The patients most commonly complain of irritative symptoms (37$99 \%)$ or mixed symptoms (34-79\%). Obstructive symptoms are seen less frequently (51-59\%) (8-11).

Upper urinary tract complications are rare in MS patients (12). The incidence of upper urinary tract involvement was
$0.34 \%$ in a study of $2076 \mathrm{MS}$ patients (10), whereas in another review it was reported to be $12 \%$ on average (8).

The most common urodynamic finding in patients with MS is detrusor hyperactivity with an average of 65\% (34-99\%). The incidence of detrusor sphincter dyssynergia (DSD) is $35 \%(5-83 \%)$ while the frequency of detrusor hypoactivity is $25 \%(0-40 \%)$ on average $(8,13-17)$. In $1-34 \%$ of symptomatic patients, no pathologic finding is observed in the urodynamic investigation $(8,18,19)$. In about $55 \%$ of the patients, the urodynamic pattern changes with time (14).

In a study of the effect of MS-related urinary symptoms on quality of life, Quarto et al. (20) investigated a group of women with urinary complaints (107 MS) and a control group including 100 women with overactive bladder symptoms but no neurological disease. Both groups were administered the King's quality of life scale (KQL), and it was found that urinary symptoms had a greater impact on quality of life in the MS group. Patients in the MS group were significantly more affected in the domains of general health perception, role limitation, physical limitation, social limitation, and urinary symptoms. 
In this study, we aimed to investigate the correlation of urinary symptoms with urodynamic findings and their effects on quality of life in patients with MS.

\section{METHODS}

\subsection{Participants}

We included 19 multiple sclerosis (MS) patients (18-65 years) who were followed at the Department of Neurology and were planned for urodynamic testing due to urinary symptoms (i.e. frequent urination, urgency, incontinence, difficulty in starting urination, straining to void, incomplete emptying, weak urine flow).

Exclusion criteria were as follows: 1 ) having an accompanying neurological disease, 2) worsening in the last 1 month, 3) having MS flare up, 4) having a urinary problem unrelated to MS, 5) having an active urinary tract infection, 6) receiving pharmacological treatment for urinary symptoms, 7) having difficulties in answering the questionnaires due to language or cognitive limitations, 8) refusing to participate in the study. Patients were informed about the study and consent was obtained before the study.

All participants provided written informed consent form and written permission from their physician allowing their participation and the hospital ethics committee had approved the study protocol.

\subsection{Outcomes}

The demographic (age, sex, occupation, education) and clinical data (age of MS onset, MS duration, MS type, bladder status at presentation, background, Expanded Disability Status Scale (EDSS) score, and EDSS bladder/bowel score) were obtained from the patient files or by face-to-face interviews.

In order to determine the effect of urinary symptoms on quality of life, the patients answered the Incontinence Quality of Life Scale (IQOL), the King's Quality of Life Scale $(K Q L)$, and the International Consultation on Incontinence Modular Questionnaire-Short Form (ICIQ-SF).

Expanded Disability Status Scale (EDSS) is one of the most commonly used evaluation forms for assessing clinical disability in MS. EDSS is an ordinal scale where a score of 0 represents a normal neurological status, 2 represents minimal disability, 4 represents moderate disability, 6 represents a need for walking aid, and 8 represents wheelchair dependence.

Incontinence Quality of Life Scale (IQOL) is an assessment tool specific for incontinence and self-administered by the patient. It is used particularly in the evaluation of stress incontinence, overactive bladder, and neurogenic detrusor overactivity. IQOL contains 22 items that address specific issues related to incontinence in particular. The items are collected in 3 domains: avoidance and limiting behaviors, psychosocial impact, and social embarrassment. Each item is scored on a scale of 5 points from 1 (severe) to 5 (none); high scores indicate better quality of life. The validity and reliability of the Turkish version has been demonstrated (21).

King's Quality of Life Scale (KQL) is a questionnaire with demonstrated validity and reliability and is of choice for patients with urinary symptoms due to the inclusion of both bladder-specific and general health questions. The questionnaire consists of three parts: Part 1 has 2 questions about the impact of general health and urinary symptoms on the quality of life, Part 2 has 19 questions that cover 7 dimensions of the quality of life (role limitations, physical limitations, social limitations, personal relationships, emotions, sleep/energy, and severity measures), and part 3 has 10 questions that measure the effect of or discomfort due to various urinary symptoms. The lowest score ' 0 ' indicates the best health condition, while the highest score ' 100 ' indicates the worst health condition. The validity and reliability study for the Turkish version of the KQL had been previously carried out with MS patients (22).

Short Form for the International Consultation on Incontinence Modular Questionnaire (ICIQ-SF) consists of 6 questions. It is a measure used to determine the frequency and severity of urinary incontinence, and its effect on the quality of life. Studies for the validity and reliability of the questionnaire in various languages were reported; a Turkish version was also demonstrated to express the quality of life (23). The scale is scored between 0 and 21 where higher scores represent greater effect on the quality of life.

\subsection{Urodynamic Evaluation}

A cystometric examination was performed in all patients with a Medical Measurement Systems urodynamics testing unit.

A double lumen cystometry catheter was used for intravesical pressure measurement and a rectal catheter $(8 \mathrm{Fr})$ for abdominal pressure measurement. $0.9 \% \mathrm{NaCl}$ was used for filling. The filling was done at physiological speed.

Before all urodynamic testing, the presence of infection was investigated with a urine culture. The urodynamic testing was performed after appropriate antibiotherapy in the patients with urinary tract infection. Patients were filled up to a maximum of $400 \mathrm{~mL}$. The testing was terminated in patients who did not have incontinence up to this volume and in those who had pain during the testing. The administration and evaluation of urodynamics were based on the criteria set by the International Continence Society (24). The maximum cystometric capacity and the maximum detrusor pressure were recorded.

\subsection{Statistical Analysis}

SPSS 15.0 program was used for statistical analyses. Descriptive statistics (mean, standard deviation) were calculated. The Mann Whitney U test was used to analyze continuous variables (age, duration of illness, EDSS score, scores from the quality of life questionnaire, urodynamic findings). Chi-square test 
was used to analyze categorical variables (sex, education, occupation, MS type, type of urinary symptom). Spearman's rho correlation coefficient was used for the correlation analysis. The significance level was set as $p<0.05$.

\section{RESULTS}

The average age at the onset of multiple sclerosis (MS) was 30 years (range $=20-59$ years). The average duration of MS was 94 months (range=14-184 months). The demographic characteristics of the patients were given in Table 1.

Table 1. Demographic characteristics of patients $(n=19)$

\begin{tabular}{|l|l|l|}
\hline $\begin{array}{l}\text { Parameters } \\
\text { Age }(\text { mean } \pm \text { SD) }\end{array}$ & $38.74 \pm 9.66$ \\
\hline Gender $(n, \%)$ & & $3(15.8)$ \\
\hline & Male & $16(84.2)$ \\
\hline Education $(n, \%)$ & Female & \\
\hline & & $6(31.6)$ \\
\hline & Primary school & $4(21.1)$ \\
\hline & Secondary school & $5(26.3)$ \\
\hline & High School & $4(21.1)$ \\
\hline & University & \\
\hline Occupation (n, \%) & & $2(10.5)$ \\
\hline \multirow{5}{*}{} & Government official & $1(5.3)$ \\
\hline & Worker & $1(5.3)$ \\
\hline & Retired & $14(73.7)$ \\
\hline & Housewife & $1(5.3)$ \\
\hline & Self-employment & \\
\hline & & \\
\hline
\end{tabular}

$S D$ : standard deviation

There were 12 patients (63.2\%) with relapsing-remitting MS, three patients (15.8\%) with primary progressive MS, three patients (15.8\%) with secondary progressive MS, and one patient $(5.3 \%)$ with progressive relapsing MS.

The mean EDSS score was 3.9 while the mean EDSS bladder score was 2.2. Six patients had irritative symptoms (31.6\%), one patient (5.3\%) had obstructive symptoms, and 12 patients (63.2\%) had mixed symptoms. Urgency and frequency were present in all patients (100\%), nocturia in $94.7 \%$ of the patients, urge incontinence in $89.5 \%$, intermittent urination in $68.4 \%$, stress incontinence in $63.2 \%$, straining to void in $52.6 \%$; difficulty in starting urination and dysuria were seen in $47.4 \%$ of the patients and enuresis nocturna in $31.6 \%$.

\section{IQOL Scale}

Table 2 shows the distribution of scores in the domains of the IQOL questionnaire. The scores from the "avoidance and limitation behavior" subscale ranged from 12 to 78 with a mean of 37.2. The scores from the "psychosocial impact" subscale ranged from 11 to 94 , with an average of 43.1 The scores from the "social embarrassment" subscale scores ranged from 5 to 85 with an average of 38.6. The average ICIQ-SF score was $8.8 \pm 4.9$ (range=0-16).

\section{King's Quality of Life Questionnaire}

The average score of General Health Perception in Part 1 of the King's Quality of Life Questionnaire (KQL) was 57.8. The average score of Incontinence Impact in Part 1 of the KQL was 75.4 (Table 2). When we look at the distribution of scores in Part 2 of King's quality of life scale, the highest score was in the "physical limitations" subscale $(73,6)$; the lowest score was in the "personal relationships" subscale $(30,3)$ (Table 2$)$. The scores of Part 3 of the KQL were presented in Table 3. The most frequently encountered symptom in this section was frequency, followed by nocturia and urgency.

Table 2. The distribution of scores in the IQOL, $1^{\text {st }}$ and $2^{\text {nd }}$ part of King's Quality of Life scale.

\begin{tabular}{|l|l|l|}
\hline Parameters & Min - Max & Mean \pm SD \\
\hline IQOL & $0-100$ & $70.42 \pm 31.85$ \\
\hline Avoidance and Limiting Behaviors & $0-100$ & $73.65 \pm 29.57$ \\
\hline Psychosocial Impacts & $0-66.6$ & $42.06 \pm 19.43$ \\
\hline Social Embarrassment & $0-100$ & $30.37 \pm 28.40$ \\
\hline KQL - Part 1 & $22.2-100$ & $59.59 \pm 23.76$ \\
\hline General Health Perception & $33.3-100$ & $61.37 \pm 28.36$ \\
\hline $\begin{array}{l}\text { Impact of Bladder Problem on the } \\
\text { Quality of Life }\end{array}$ & $25-100$ & $55.23 \pm 22.25$ \\
\hline KQL - Part 2 & $0-100$ & $70.42 \pm 31.85$ \\
\hline Role Limitations & $0-100$ & $70.42 \pm 31.85$ \\
\hline Physical Limitations & $0-100$ & $73.65 \pm 29.57$ \\
\hline Social Limitations & $0-66.6$ & $42.06 \pm 19.43$ \\
\hline Personal Relationships & $0-100$ & $30.37 \pm 28.40$ \\
\hline Emotions & $22.2-100$ & $59.59 \pm 23.76$ \\
\hline Sleep/Energy & $33.3-100$ & $61.37 \pm 28.36$ \\
\hline Severity Measures & $25-100$ & $55.23 \pm 22.25$ \\
\hline
\end{tabular}

IQOL: Incontinence Quality of Life Scale, KQL: King's Quality of Life Scale, SD: standard deviation

\section{ICIQ-SF Questionnaire}

The ICIQ-SF score ranged from 0 to 16 points, with an average of $8.84 \pm 4.92$.

\section{Results of urodynamic testing}

The urodynamic testing revealed that bladder capacity of the patients was $311 \pm 122 \mathrm{ml}$ (range $=31-479 \mathrm{ml}$ ). Five patients (26.3\%) had normal urodynamic findings, one patient $(5,3 \%)$ had detrusor hyperactivity, 11 patients (57.9\%) had detrusor hyperactivity + detrusor sphincter dyssynergia (DSD), and two patients (10.5\%) had sensorial urgency.

\section{Differences in evaluation parameters according to MS types}

No significant difference was found between the MS types in terms of MS duration, quality of life scale scores, symptom type, and urodynamic test results ( $p>0.05)$ (Table 3 ). 
Table 3. The distribution of scores in the $3^{\text {rd }}$ part of King's Quality of Life scale.

\begin{tabular}{|c|c|c|c|c|}
\hline \multirow{2}{*}{ Parameters } & \multicolumn{4}{|c|}{ Presence and severity of the symptoms } \\
\hline & Absent & A little & Moderately & A lot \\
\hline Frequency (n, \%) & & $2(10.5 \%)$ & $4(21.1 \%)$ & $\begin{array}{l}1 \\
(68.4 \%)\end{array}$ \\
\hline Nocturia $(n, \%)$ & $1(5.3 \%)$ & $6(31.6 \%)$ & $5(26.3 \%)$ & $7(36.8 \%)$ \\
\hline Urgency (n, \%) & - & $1(5.3 \%)$ & $12(63.2 \%)$ & $6(31.6 \%)$ \\
\hline $\begin{array}{l}\text { Urge incontinence } \\
(n, \%)\end{array}$ & $2(10.5 \%)$ & $3(15.8 \%)$ & $9(47.4 \%)$ & $5(26.3 \%)$ \\
\hline $\begin{array}{l}\text { Stress } \\
\text { incontinence } \\
(n, \%)\end{array}$ & $7(36.8 \%)$ & $7(36.8 \%)$ & $4(21.1 \%)$ & $1(5.3 \%)$ \\
\hline $\begin{array}{l}\text { Nocturnal } \\
\text { enuresis }(n, \%)\end{array}$ & $13(68.4 \%)$ & $3(15.8 \%)$ & $1(5.3 \%)$ & $2(10.5 \%)$ \\
\hline $\begin{array}{l}\text { Intercourse } \\
\text { incontinence } \\
(n, \%)\end{array}$ & $17(89.5 \%)$ & - & $2(10.5 \%)$ & - \\
\hline Dysuria $(n, \%)$ & $10(52.6 \%)$ & $2(10.5 \%)$ & $6(31.6 \%)$ & $1(5.3 \%)$ \\
\hline $\begin{array}{l}\text { Straining to void } \\
(n, \%)\end{array}$ & $9(47.4 \%)$ & $3(15.8 \%)$ & $4(21.1 \%)$ & $3(15.8 \%)$ \\
\hline
\end{tabular}

\section{Correlation between EDSS score and quality of life scores:}

There was a statistically significant correlation only between the EDSS score and Role Limitation subscale of the KQL $(p<0.05)$ (Table 4).

Table 4. Correlations between EDSS score and quality of life scores.

\begin{tabular}{|c|c|c|}
\hline & $r$ & $p$ \\
\hline $\begin{array}{l}\text { IQOL } \\
\text { Avoidance and Limiting Behaviors } \\
\text { Psychosocial Impacts } \\
\text { Social Embarrassment }\end{array}$ & $\begin{array}{l}-0.075 \\
-0.395 \\
-0.164\end{array}$ & $\begin{array}{l}0.760 \\
0.094 \\
0.502\end{array}$ \\
\hline $\begin{array}{l}\text { KQL - Part } 1 \\
\text { General Health Perception } \\
\text { Impact of Bladder Problem on the Quality of Life }\end{array}$ & $\begin{array}{l}0.325 \\
0.360\end{array}$ & $\begin{array}{l}0.175 \\
0.158\end{array}$ \\
\hline $\begin{array}{l}\text { KQL - Part } 2 \\
\text { Role Limitations } \\
\text { Physical Limitations } \\
\text { Social Limitations } \\
\text { Personal Relationships } \\
\text { Emotions } \\
\text { Sleep/Energy } \\
\text { Severity Measures }\end{array}$ & $\begin{array}{l}0.498 \\
0.337 \\
0.085 \\
0.413 \\
0.394 \\
-0.001 \\
0.074\end{array}$ & $\begin{array}{l}0.030 * \\
0.158 \\
0.729 \\
0.100 \\
0.095 \\
0.997 \\
0.763\end{array}$ \\
\hline ICIQ-SF & 0.329 & 0.169 \\
\hline
\end{tabular}

IQOL: Incontinence Quality of Life Scale, KQL: King's Quality of Life Scale, ICIQ-SF: International Consultation on Incontinence Modular Questionnaire-Short Form. ${ }^{*} p<0.05$

Differences between the symptom types in terms of the evaluation parameters and the results of urodynamic testing

No significant difference was found between the symptom types in terms of quality of life scores $(p>0.05)$. In the results of urodynamic testing, while no significant difference was found between irritative and mixed type symptoms in terms of maximum detrusor pressure, bladder capacity of patients with irritative symptoms was statistically higher than bladder capacity of those with mixed symptoms ( $<<0.05)$ (Table 5). Ayrıca; the normal urodynamic test findings were higher among the patients with irritative symptoms while abnormal urodynamic findings were higher among the patients with mixed symptoms (Table 5).

Table 5. Differences in the evaluation parameters and the results of urodynamic testing according to the symptom types.

\begin{tabular}{|c|c|c|c|}
\hline & \multicolumn{3}{|l|}{ Symptom Type } \\
\hline & Irritative & Mixed & $p$ \\
\hline EDSS (mean $\pm S D$ ) & $3.67 \pm 1.60$ & $3.79 \pm 2.02$ & 0.962 \\
\hline $\begin{array}{l}\text { IQOL (mean } \pm \text { SD) } \\
\text { Avoidance and Limiting } \\
\text { Behaviors } \\
\text { Psychosocial Impacts } \\
\text { Social Embarrassment }\end{array}$ & $\begin{array}{l}40.33 \pm 19.83 \\
40.33 \pm 20.55 \\
38.33 \pm 12.91\end{array}$ & $\begin{array}{l}34.58 \pm 17.86 \\
45.42 \pm 25.94 \\
38.75 \pm 22.37\end{array}$ & $\begin{array}{l}0.572 \\
0.708 \\
0.962\end{array}$ \\
\hline $\begin{array}{l}\text { KQL - Part } 1 \text { (mean } \pm S D \text { ) } \\
\text { General Health Perception } \\
\text { Impact of Bladder Problem on } \\
\text { the Quality of Life }\end{array}$ & $\begin{array}{l}54.17 \pm 29.22 \\
72.18 \pm 25.11\end{array}$ & $\begin{array}{l}60.42 \pm 16.71 \\
77.75 \pm 25.97\end{array}$ & $\begin{array}{l}0.958 \\
0.612\end{array}$ \\
\hline $\begin{array}{l}\text { KQL - Part } 2 \text { (mean } \pm \text { SD) } \\
\text { Role Limitations } \\
\text { Physical Limitations } \\
\text { Social Limitations } \\
\text { Personal Relationships } \\
\text { Emotions } \\
\text { Sleep/Energy } \\
\text { Severity Measures }\end{array}$ & $\begin{array}{l}63.87 \pm 40.02 \\
69.41 \pm 35.60 \\
38.86 \pm 24.06 \\
16.64 \pm 16.65 \\
48.10 \pm 13.44 \\
52.75 \pm 30.59 \\
56.91 \pm 11.09\end{array}$ & $\begin{array}{l}71.23 \pm 28.78 \\
74.97 \pm 28.88 \\
58.27 \pm 53.99 \\
30.28 \pm 24.50 \\
62.90 \pm 26.08 \\
62.46 \pm 26.71 \\
56.22 \pm 26.61\end{array}$ & $\begin{array}{l}0.736 \\
0.664 \\
0.705 \\
0.242 \\
0.142 \\
0.399 \\
0.850\end{array}$ \\
\hline ICIQ-SF (mean \pm SD) & $9.83 \pm 5.06$ & $9.08 \pm 4.52$ & 0.572 \\
\hline Bladder Capacity (mean $\pm S D$ ) & $\begin{array}{l}388.33 \pm \\
84.88\end{array}$ & $268 \pm 124.88$ & $0.025^{*}$ \\
\hline $\begin{array}{l}\text { Maximum Detrusor Pressure } \\
\text { (mean } \pm S D \text { ) }\end{array}$ & $21.50 \pm 27.99$ & $47.33 \pm 48.71$ & 0.159 \\
\hline $\begin{array}{l}\text { Result of Urodynamic Testing } \\
(\mathrm{n}, \%) \\
\text { Normal } \\
\text { Abnormal }\end{array}$ & $\begin{array}{l}4(80) \\
2(15.4)\end{array}$ & $\begin{array}{l}1(20) \\
11(84.6)\end{array}$ & $0.022^{*}$ \\
\hline
\end{tabular}

IQOL: Incontinence Quality of Life Scale, KQL: King's Quality of Life Scale, ICIQ-SF: International Consultation on Incontinence Modular QuestionnaireShort Form, SD: standard deviation, ${ }^{*} p<0.05$.

\section{Differences in the evaluation parameters according to urodynamic examination results}

Patients with normal and abnormal urodynamic results did not differ significantly in terms of their scores on the IQOL, Part 1of KQL, and ICIQ-SF. However, the scores of the patients with abnormal urodynamics were significantly higher in the emotions and sleep/energy domains of the KQL $(p<0.05)$ (Table 6). 
Table 6. Differences in the evaluation parameters according to the results of urodynamic testing.

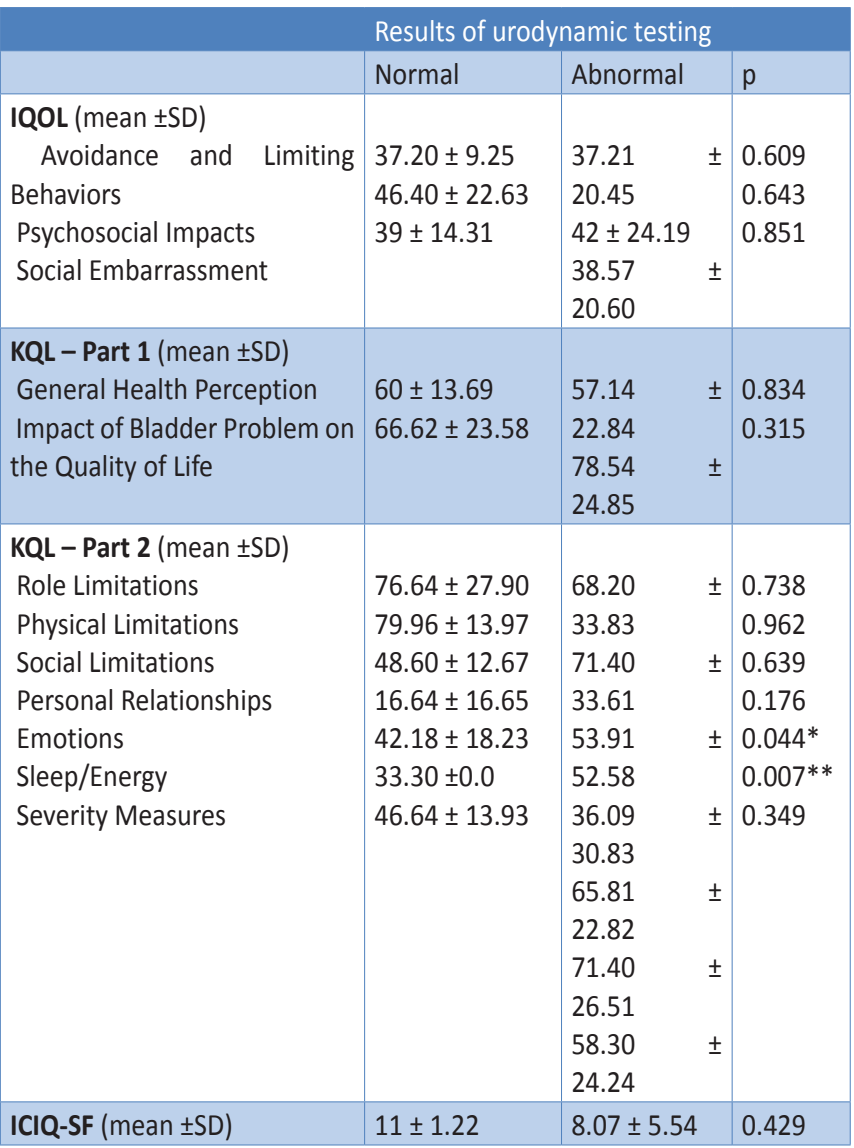

IQOL: Incontinence Quality of Life Scale, KQL: King's Quality of Life Scale, ICIQ-SF: International Consultation on Incontinence Modular QuestionnaireShort Form, SD: standard deviation, ${ }^{*} p<0.05,{ }^{* *} p<0.01$

\section{DISCUSSION}

In our study, neither multiple sclerosis (MS) type nor MS duration had a correlation with urinary symptoms, quality of life, or urodynamic findings. Nakipoğlu et al. (6) evaluated the correlation between urinary symptoms and urodynamic findings in 52 patients. They also did not find a correlation between MS type and urinary symptoms and urodynamic findings. However, they reported a higher disease duration and age among the patients with urinary symptoms. Similar results were also reported by Award et al. (25). The lack of similar results in our study can be explained by the shorter disease duration and the lower functional disability scores among our patients. The expanded disability status scale (EDSS) score in that study was $5.1 \pm 2.2$, which was $3.89 \pm$ 1.90 in our study.

Porru et al. (26) showed a correlation between the MS duration and urodynamic findings, particularly the frequency of detrusor sphincter dyssynergia (DSD) increased with the MS duration. The rate of DSD in this study was $13 \%$ in the 48th month and increased to $48 \%$ in the 109th month. This finding has been supported by other studies $(8,14,27)$. In contrast, Ukkonen and colleagues (28) have not found any correlation between the MS duration and urodynamics. The mean duration of illness in our study was $94 \pm 49$ months. We think that due to the shorter disease duration in our patients, we did not find similar results.

In our study, there was no correlation between the EDSS scores and urinary symptoms and urodynamic findings. There was a statistically significant correlation only between the EDSS score and the 'role limitations' subscale of the King's Quality of Life Questionnaire (KQL). Previous publications on this issue are contradictory. While some studies have shown an association between the EDSS and urinary symptoms (9, $15,29)$, the others failed to demonstrate a correlation (30). While some studies did not find a correlation between the EDSS and the urodynamic test results $(8,31)$, other studies have found a relationship between the presence of DSD and the EDSS scores $(32,33)$. This relationship can be explained by the fact that MS is a progressive disease, and although the urodynamic parameters show variability (14), the DSD is stable (8). Therefore, as the disease progresses, an increase in the DSD frequency and the EDSS scores may be expected.

Differences in the EDSS scores between studies may have been caused by different inclusion criteria and functional differences of patients. We think that the reason for the lack of correlation in our study might be due to the better functional status and the lower EDSS score of the patients in our study.

The frequency of urinary symptoms is reported to be 52 $97 \%$ in patients with MS (3-4). Most of the patients have irritative symptoms (37-99\%). In our study, however, most patients had mixed symptoms (63.2\%), followed by irritative symptoms (31.6\%). In our study, only one patient had obstructive symptoms (5.3\%). This prevented us from making comparisons between the patients with obstructive symptoms and those with other symptoms. These findings may be related to the low number of participants and the patient selection criteria in our study.

In our study, while an effect on the quality of life was detected in all patients regardless of urinary symptom type, there was no relationship between the urinary symptoms and the subscales of the quality of life questionnaires.

When the urodynamic testing results were evaluated, the bladder capacity was found to be significantly higher in the patients with irritative symptoms than those with mixed type symptoms. In addition, the percentage of the normal urodynamic testing result was higher in the patients with irritative symptoms. The abnormal urodynamic findings were obtained in $84.6 \%$ of the patients with mixed urinary symptoms. This result also explains why the bladder capacity of patients with irritative symptoms was significantly higher than that of the patients with mixed symptoms in our study. Previous publications on this issue are contradictory. Although a few studies have shown weak correlations between the urinary symptoms and the urodynamic findings $(6,28,34,35$, $36)$, there was no correlation between the urinary symptoms and the urodynamic findings in most studies $(8,11,13,14,18$, $37,38)$. 
The most common urodynamic neurogenic bladder finding in MS patients was detrusor overactivity with an average of $65 \%(34-99 \%)$, while the frequency of detrusor overactivity + DSD was $35 \%$ (5-83\%). The frequency of decreased detrusor activity is $25 \%(0-40 \%)$ on average $(8,13-17)$. In $1-34 \%$ of the symptomatic patients, a normal urodynamics is found (8, $18,19)$. In a meta-analysis of 1900 patients, the most common urodynamic anomaly was detrusor hyperactivity (62\%) (12).

In our study, no relation was found between the ICIQ-SF and I-QOL questionnaires and the urodynamic parameters. Only a statistically significant relationship was found between the 'emotions' and 'sleep/energy' subscale scores of the KQL and the abnormal urodynamic test results. This relationship may have occurred, especially in the presence of underlying neurogenic bladder pathology, due to the symptoms that continue even at nights and affect the sleep pattern of the patients, affecting the patients' scores in both the 'sleep/ energy' and the 'emotions' subscales.

Quarto et al. (20) investigated the effect of urinary symptoms on quality of life among 107 female MS patients with the urinary symptoms and 100 women with the overactive bladder symptoms without a neurological disease. Both groups answered the KQL. As a result, it was found that the urinary symptoms in the MS group had more effect on the quality of life in the KQL, and patients in the MS group were found to be affected significantly more by general health perception, role limitations, physical limitations, social limitations, and urinary symptoms. Espuna Pons et al. (39) evaluated 674 female patients with urinary symptoms with the KQL and reported that the urinary symptoms affect all domains and impair their quality of life.

Eyigör et al. (21) evaluated the Incontinence Quality of Life Scale (IQOL) scores in MS patients. In this study, the 'avoidance' and the 'limiting behavior' score was $26.9 \pm$ 8.8 the 'psychosocial impact' score was $33.3 \pm 10.4$ and the 'social embarrassment' score was $18.7 \pm 6.0$. While an effect was detected in all subscales of the quality of life in our study, the most effect was seen in the 'avoidance' and the 'limiting behavior' subscales in IQOL (37.2 \pm 17.9$)$. In the KQL, the most significant effect was in the 'To what extent does your bladder problem affect your household tasks?' question $(75.0 \pm 24.4)$. This can be regarded as an expected finding since the patients in the study were in a good functional status and their actual problems were the urinary symptoms.

Since we could not locate a study that used the ICIQ-SF on MS patients in the literature, we could not draw a comparison. However, in one study involving women with urinary incontinence in Turkey, it has been reported that the ICIQ-SF shows strong similarity with the I-QOL questionnaire and that the ICIQ-SF alone may be sufficient in measuring the quality of life (40). In addition, in another study involving 103 female patients with incontinence, Pons et al. compared the KQL and ICIQ-SF and reported similar specificity and sensitivity of both surveys in both types of incontinence (41). They suggested that the ICIQ-SF might be used in clinical practice with confidence since the KQL takes longer time to complete. In light of this information, the use of the ICIQ-SF in assessing the impact of incontinence on the quality of life in MS patients seems appropriate; however, this questionnaire requires further study to confirm its validity and reliability in MS patients.

Another debate in the management of MS patients with urinary symptoms is the use of urodynamic tests in the diagnosis and follow-up. Some authors do not recommend urodynamic investigation at primary care since the upper urinary tract involvement is less common than other neurogenic bladder diseases and due to cost-benefit analysis (42). On the other hand, others note that the elevations and persistence of detrusor pressure in particular are a major risk factor for the upper urinary tract involvement in MS patients; pointing out that the urodynamic pattern changes in MS patients, they also suggest the urodynamic examination as a routine in diagnosis and treatment (8). Similarly, although there was not enough evidence, Çetinel et al. (43) summarized the justifications in studies recommending urodynamic testing at primary care as: 1 ) the maximum detrusor pressure in the MS patients with upper urinary tract involvement is higher than those without, 2) there is no correlation between urinary symptoms and urodynamic findings, 3) the urinary dysfunction pattern may change over time, 4) $50 \%$ of MS patients without urinary symptom has abnormality in urodynamic tests, and 5) an appropriate treatment can be planned only after a urodynamic test.

As seen in the literature, the upper urinary tract involvement is quite rare in MS patients. While the incidence of the upper urinary tract involvement was $0.34 \%$ in a study in which 2076 MS patients were evaluated (10), it was reported to be $12 \%$ on average in another review (8). In our study, none of the patients had upper urinary tract involvement according to ultrasonography performed before the urodynamic tests. This may be because detrusor pressures in MS patients are lower than those in other neurogenic bladder diseases and there may be alterations in the bladder pathology and pressures during the remission periods. $(14,44)$ In the MS patients with urinary symptoms, a detailed query of medical history and neuro-urological examination, evaluation of voiding diary, complete urine and serum creatinine level analysis, urinary system ultrasonography, and the postvoid residual urine volume (PVR) measurements are appropriate. The urodynamic examination is required in order to confirm the underlying pathology if conservative treatment fails and/ or the upper urinary tract is involved.

As a result, the physician will consider these factors and decide on the necessity of urodynamic tests according to patient's clinical findings and expectation.

One of the limitations of our study is the low number of patients. Another limitation is that the number of male patients was low in our study. This situation has prevented us from making the comparison of parameters in terms of gender. Since the number of participants was low and due to the selection criteria, only one patient had obstructive symptoms in our study, which hindered the evaluation of 
obstructive type symptoms during the comparison of urinary symptoms with other parameters.

\section{CONCLUSION}

Symptoms related to urinary dysfunction are a major problem affecting the quality of life of an individual with MS. Because there is not always a constant relation between symptoms and the underlying pathology, it seems more appropriate to give treatment according to the bladder type detected after urodynamic testing.

\section{REFERENCES}

[1] Lassmann H, Brück W, Lucchinetti CF. The immunopathology of multiple sclerosis: an overview. Brain Pathol 2007; 17: 210218.

[2] Nortvedt MW, Riise T, Myhr KM, Landtblom AM, Bakke A, Nyland HI. Reduced quality of life among multiple sclerosis patients with sexual disturbance and bladder dysfunction. Mult Scler 2001; 7: 231-235.

[3] Gunduz B, Erhan B, Demir Y, Coskun E, Tekin N. Neurogenic bladder in multiple sclerosis. Turk J Phys Med Rehab 2006; 52: 102-104.

[4] Taylor RS. Rehabilitation of persons with multipl sclerosis. Braddom RL, editor. Physical Medicine and Rehabilitation. Philadelphia PA: Saunders; 2000.p.1177-1190.

[5] Fingerman S, Finkelstein H. The overactive bladder in multiple sclerosis. J Am Osteopath Assoc 2000; 100: 9-12.

[6] Nakipoglu GF, Kaya AZ, Orhan G, Tezen O, Tunc H, Ozgirgin N, Ak F. Urinary dysfunction in multiple sclerosis. J Clin Neurosci 2000; 16: 1321-1324.

[7] Miller AE, Lublin FD, Coyle PK. Multiple sclerosis in clinical practice. New York: Taylor and Francis Group; 2003.

[8] De Sèze M, Ruffion A, Denys P, Joseph PA, Perrouin-Verbe B. The neurogenic bladder in multiple sclerosis: review of the literature and proposal of management guidelines. Mult Scler J 2007; 13: 915-928.

[9] Onal B, Siva A, Buldu I, Demirkesen O, Cetinel B. Voiding dysfunction due to multiple sclerosis: a large scale retrospective analysis. Int Braz J Urol 2009; 35: 326-333.

[10] Koldewijn EL, Hommes OR, Lemmens WA, Debruyne FM, van Kerrebroeck PE. Relationship between lower urinary tract abnormalities and disease-related parameters in multiple sclerosis. J Urology 1995; 154: 169-173.

[11] Gallien P, Robineau S, Nicolas B, Le Bot MP, Brissot R, Verin $M$. Vesicourethral dysfunction and urodynamic findings in multiple sclerosis: a study of 149 cases. Arch Phys Med Rehabil 1998; 79: 255-257.

[12] Kalsi V, Fowler CJ. Therapy insight: bladder dysfunction associated with multiple sclerosis. Nat Clin Pract Urol 2005; 10: 492-501.

[13] Amarenco G, Kerdraon J. Bladder and sphincter dysfunction in multiple sclerosis. Clinical, urodynamical and neurophysiologic study of 225 cases. Rev Neurol 1995; 151: 722-730.

[14] Cianco S, Mutchnik S, Rivera V, Boone TB. Urodynamic pattern changes in multiple sclerosis. Urology 2001; 57: 239-245.

[15] Araki I, Matsui M, Ozawa K, Takeda M, Kuno S. Relationship of bladder dysfunction to lesion site in multiple sclerosis. J Urology 2003; 169: 1384-1387.
[16] Hinson JL, Boone TB. Urodynamics and multiple sclerosis. Urol Clin N Am 1996; 23: 475-481.

[17] Barbalias GA, Nikiforidis G, Liatsikos EN. Vesicourethral dysfunction associated with multiple sclerosis: clinical and urodynamic perspectives. J Urology 1998; 160: 106-111.

[18] Litwiller SE, Frohman M, Zimmern PE. Multiple sclerosis and the urologist. J Urology 1999; 161: 743-757.

[19] Leboeuf L, Gousse AE. Multiple sclerosis. Corcos J, Schick E, editors. Textbook of neurogenic bladder. Adults and children. London: Martin Dunitz/Taylor \& Francis Group; 2004.p.275292.

[20] Quarto G, Autorino R, Gallo A, De Sio M, D’Armiento M, Perdonà S, Damiano R. Quality of life in women with multiple sclerosis and overactive bladder syndrome. Int Urogynecol J Pelvic Floor Dysfunct. 2007 Feb;18(2):189-94

[21] Eyigor S, Karapolat H, Akkoc Y, Yesil H, Ekmekci O. Quality of life in patients with multiple sclerosis and urinary disorders: reliability and validity of Turkish-language version of Incontinence Quality of Life Scale. J Rehabil Res Dev. 2010;47(1):67-71.

[22] Akkoc $Y$, Karapolat H, Eyigor S. Quality of Life in Multiple Sclerosis Patients with Urinary Disorders: Reliability and Validity of the Turkish version of King's Health Questionnaire, has been accepted for publication in Neurological Sciences 2011.

[23] Çetinel B, Özkan B, Can G: ICIQ-SF Türkçe Versiyonu Validasyon (Geçerlilik) Çalısması. Türk Üroloji Dergisi 2004, 30:332-338(Turkish).

[24] Abrams P, Cardozo L, Fall M, Griffiths D, Rosier P, Ulmsten $U$, Van Kerrebroeck P, Victor A, Wein A. The standardisation of terminology of lower urinary tract function: report from the Standardisation Sub-committee of the International Continence Society. Am J Obstet Gynecol 2002; 187: 116-126.

[25] Award SA, Gajewski JB, Sogbein SK, Murray TJ, Field CA. Relationship between neurological and urological status in patients with multiple sclerosis. J Urology 1984; 132: 499-502.

[26] Porru D, Campus G, Garau A, Sorgia M, Pau AC, Spinici G. Urinary tract dysfunction in multiple sclerosis: is there a relation with disease-related parameters? Spinal Cord 1997; 35: 33-36.

[27] Wheeler JS, Siroky MB, Pavlakis AJ, Goldstein I, Krane RJ. The changing neurological pattern of multiple sclerosis. J Urology 1983; 130: 1123-1126.

[28] Ukkonen M, Elovaara I, Dastidar P, Tammela TLJ. Urodynamic findings in primary progressive multiple sclerosis are associated with increased volumes of plaques and atrophy in the central nervous system. Acta Neurol Scand 2004; 109: 100105.

[29] Giannantoni A, Scivoletto G, Di Stasi SM, Grasso MG, Agrò EF, Collura G, Vespasiani G. Lower urinay tract dysfunction and disability status in patients with multiple sclerosis. Arch Phys Med Rehabil 1999; 80: 437-441.

[30] Goldstein I, Siroky MB. Neurourologic abnormalities in multiple sclerosis. J Urology 1982; 128: 541-545, Miller H, Simpson CA, Yeates WK. Bladder dysfunction in multiple sclerosis. BMJ Brit Med J 1965; 1: 1265-1269.

[31] Barbalias GA, Liatsikos EN, Passakos C, Barbalias D, Sakelaropoulos G. Vesicourethral dysfunction associated with multiple sclerosis: Correlations among response, most prevailing clinical status and grade of the disease. Int Urol Nephrol 2001; 32: 349-352. 
[32] Betts C, Mellow M, Fowler C. Urinary symptoms and the neurological features of bladder dysfunction in multiple sclerosis. J Neurol Neurosurg Psychiatry 1993; 56: 245-250.

[33] Giannantoni A, Scivoletto G, Di Stasi SM, Grasso MG, Vespasiani G, Castellano V. Urological dysfunctions and upper urinary tract involvement in multiple sclerosis patients. Neurourol Urodyn 1998; 17: 89-98.

[34] Goldstein I, Siroky MB. Neurourologic abnormalities in multiple sclerosis. J Urology 1982; 128: 541-545.

[35] Blavias JG, Bhimani G, Labib KB. Vesicourethral dysfunction in multiple sclerosis. J Urology 1979; 3: 342-347.

[36] Andersson PB, Goodkin DE. Gluco-corticosteroid therapy for multiple sclerosis: A critical review. J Neurol Sci 1998; 160: 16-25.

[37] Petersen T, Pedersen E. Neurourodynamic evaluation of voiding dysfunction in multiple sclerosis. Acta Neurol Scand 1984; 69: 402-411.

[38] Philp T, Read J, Higson R. The urodynamic characteristics of multiple sclerosis. Br J Urology 1981; 53: 672-675.

[39] Espuña Pons M, Puig Clota M. Lower urinary tract symptoms in women and impact on quality of life. Results of the application of the King's Health Questionnaire. Actas Urol Esp 2006; 30: 684-691.
[40] Mertoğlu O, Süral YS, Sarı D, Zorlu F. İdrar kaçıran bayanlarda ICIQ-Kısa formundaki günlük yaşamı etkilenme skalası hayat kalitesine ne kadar etki gösteriyor? I-QOL formu ile karşılaştırma. 2. Sağlıkta Yaşam Kalitesi Kongresi, 5-7 Nisan 2007(Turkish).

[41] Espuña Pons M, Castro Díaz D, Carbonell C, Dilla T. Comparison between the "ICIQ-UI Short Form" Questionnaire and the "King's Health Questionnaire" as assessment tools of urinary incontinence among women Actas Urol Esp. 2007;31(5):50210.

[42] Fowler CJ, Panicker JN, Drake M, Harris C, Harrison SC, Kirby M, Lucas M, Macleod N, Mangnall J, North A, Porter B, Reid $\mathrm{S}$, Russell N, Watkiss K, Wells M. A UK consensus on the management of the bladder in multiple sclerosis. J Neurol Neurosurg Psychiatry 2009; 80: 470-477.

[43] Çetinel B, Tarcan T, Demirkesen O, Özyurt C, Şen I, Erdoğan $S$, Siva A. Management of lower urinary tract dysfunction in multiple sclerosis: a systematic review and Turkish consensus report. Neurourol Urodynam 2013; 32: 1047-1057.

[44] Lemarck GE, Frohman E, Ramnarayan P. Women with voiding dysfunction secondary to bladder outlet dyssynergia in the setting of multiple sclerosis do not demonstrate significantly elevated intravesical pressures. Urology 2007; 69: 893-897. 